\title{
" بواقي المنسوجات ولغة التعبير الفنى "
}

دكتور / أشرف عبد الفتاح مصطفى سعيد

\section{المدهمة ومشكالة البمث :}

منذ آلاف السنين وحتى الآن والإنسان يسعى إلى المعرفة ويبحث جاد عنها ليعرف منظومة العالم الأي يحيط به والتراث الذي يرسم هويته والمستقبل الذي يشكل حضارته فتنشأ الاستمرارية والتواصل الذى ينصب محورهما على مدى معرفة الأجيال المتتالية وتقديرهم لقيمة ماضيهم ، ومدى مساهمتهم فى صنع حاضر هم وتطوير مستقبلهم بما يساعد على التنمية التى ينشدها المجتمع ، ولقد أحرز الإنسان تقدماً ملحوظاً ونجاحاً واضحاً فى التحكم والتعايش مع البيئة وتطويعها وفقاً لمتطلباته ، وبدلاً من أن يصبح كما كان بالأمس كائناً عار خائفاً مما يحيط به ، أصبح اليوم مسيطراً على مجريات الأمور عن طريق حل مشاكله وابتكار المنتجات والوسائل التى تعينه على إعالة الحياة والسيطرة علي الطبيعة ومشاكلها لارجة ظنه أنه سخر هذه الطبيعة وسيطر عليها ولكنه للأسف ونتيجة للتفاعلات القائمة بينه وبين البيئة اكتثف مؤخراً أنه أصبح ضحية ابتكاراته وبدلاً من أن بحمى مستقبله إذ به يهدده ويكاد يدمره ، بل وأصبحت ابتكار اته نفسها فى خطر مما أحثثه من خلل فى الاتزان الطبيعى للبيئة .

وإذا كان أجدادنا الفراعنة تركوا لنا ميراثاً ما زال يشهر بمقدرتهم على الحفاظ على ما أبدعوه وأنتجوه ، فنحن أولى الناس بتحقيق هذا الجانب فى بيئتنا ومنتجاتنا حيث ينصب اهتمام معظم المصممين أثناء إبداعهم وتصميمهم للمنتجات على الجوانب الجمالية والاستخدامية والتقتية ..... إلخ بينما تهمل العلاقة المتبادلة بين 
البيئة والمنتج مما يؤدى إلى التأثير السلبى على البيئة وتلوثها فضلا عن فقدان

حضارتنا الماضية والمعاصرة (v)

فعندما خلق الله سبحانه وتعالى الكون أو البيئة الطبيعية خلقها فى حالة توازن تام حيث أن كل عنصر من عناصر هذه البيئة خلق بصفات محددة وبحجم معين بما يكفل للبيئة توازنها حيث قال فى كتابه الكريم " والأرض مددناها وألقينا فيها رواسى وأنبتنا فيها من كل شىع موزون " ( الحجر 9 1) ، وينص المفهوم العلمى الحديث للتلوث على أنه " إفساد مكونات البيئة حيث تتحول هذه المكونات من عناصر مفيدة إلى عناصر ضارة وملوثات بما يفقدها دورها فى الحياة () .

ومع بداية الألفية الثالثة والتقام التقنى السريع الأى أثز بالإيجاب فى أنماط حياتـا بلرجة كبيرة وبالسلب فى التأثيرات التى يمكن أن تتعرض لها البيئة ، هذا ويعد التلوث البيئى واحدة من التى تواجه الانسانية إذ يتخلف عن المجتمعات العمرانية ذات الكثافة السكانية العالية ملايين الأطنان من النفايات فى صور مختلفة منها ماهو فى صورة غازية مثل أول أكسيا الكربون وأخرى فى صورة سائلة مثل مياه الصرف الصحى وثالث فى صورة صلبة تشمل بواقى المنسوجات بشتى أنواعها والورق والزجاج والمنتجات البلاستيكية والألمونيوم والصلب بالإضافة إلى الضوضاء والاشعاع والمطر الحمضى ومبيدات الآفات وبعض الفلزات مثل الزئبق والرصاص ، ونظراً لأن النفايات تؤثر سلباً على البيئة إذا لم يتم التخلص منها بطريقة سليمة ، هذا وتمثل النفايات الصلبة موضوع بحثنا مشكلة خطيرة لأن معظم الطرق التى تستخدم للتخلص منها تتسبب فى تلمير البيئة ، فارتفاع درجة حرارة الأرض يساعد على تدمير طبقة الأوزون ويسبب الهواء شديد التلوث المرض وربما يفضى إلى الموت ، والماء الملوث يقتل السمك والأحياء البحرية الأخرى وتلوث التربة يقلل مساحة الأرض المتوافرة لزراعة المحاصيل الغذائية ، وحينما توضع النفايات فى أماكن مكثوفة فإنها تفسد جمال المناطق المحيطة لعالمنا الطبيعى وتوفر هذه الأماكن أيضاً مأوى ومنبت للحشرات والحيوانات حاملة الأمر اض للإنسان(· (1) 
ـ هذا وينتج عن معظم المنتجات الصناعية بعض أثكال التلوث التى تختلف من مرحلة

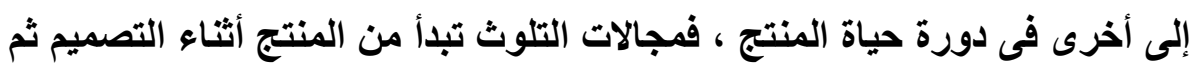
أثناء الاستخدام ثم المنتج بعد العمر الاستهلاكى ، وفى كل مرحلة من هذه المراحل يجب على المصمم القنان وضع الطرق والأساليب التى يمكن أن يعالج بها منشأ التلوث وإعداد الحلول المناسبة للتخلص من آثار ها أو تجنب حدوثها (v) وفى صناعة المنسوجات كثيرا ما تتتج أشكالاً مختلفة من النفايات أثناء عمليات التصنيع المختلفة والأمثلة التالية توضح صور هذه النفايات : 1 - الخيوط المستهكة أثناء عمليات التسدية.

r - الخيوط المستهكة أثناء عمليات التدويرات وتحضيرات خيوط اللحمة . r - فى ماكينات النسيج الحديثة ذات البراسل المقصوصة كثيراً ما تستهلك خيوط

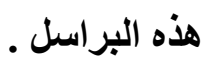
ع - الخيوط المستهلكة أثناء عملية التقديم على الأنوال .

• ـ الخيوط المستهلكة للسداء فى آخر ثوب القماش وعند " تقشيط الأنوال " 7 - الأقمشة المستهلكة فى بداية ونهاية مطاوى الأقمشة فى مصانع النسيج . V - إستهلاك الخيوط أثناء عملية الصباغة . ^ - الأقمشة المستهلكة فى بداية ونهاية عمليات الصباغة والطباعة فى المصاتع . 9 - نفايات الأقمشة الناتجة من مصانع الملابس الجاهزة . . 1 - نفايات الخيوط من مصانع السجاد والكليم . 11 - نفايات الأقمشة والملابس بعد إستخدامها . r ا I - الصبغات بمختلف فصائلها وحالاتها . هذا وتعد كل أشكال النفايات الصلبة السابق ذكرها المتمثلة فى بواقى المنسوجات من غزول وأقششة مختلفة الشكل واللون والوزن والتوع والتى قد تذهب هباء صوراً 
من التلوث البئى وخاصة ونحن نستورد جزء منها بالعملة الغير محلية(؟) لذا تمثلت الجهود الدولية فى عقد مؤتمرات دولية ، وعقد أول مؤتمر لحماية البيئة تحت إثراف الأمم المتحدة عام Q IVY بمدينة إستكهولم تدعو إلى تثجيع التعاون العالمى لمحاربة التلوث ، وفى شهر يونيو ب 9 و 1 عقد مؤتمر الأمم المتحدة الخاص بالبيئة والتنمية ( قمة الأرض ) فى مدينة ريودى جانيرو بالبرازيل ـ هذا وتستخدم الهيئات المحلية طريقتين للتخلص من النفايات الصلبة المحلية : 1 - التخلص الأرضى من النفايات . r- الترميد ( أى حرق النفايات ) وتحويلها إلى رماد .

بالإضافة إلى توافر كميات هائلة من بواقى المنسوجات كنفايات صلبة من مخلفات

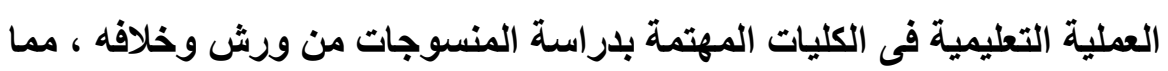
دفعنى إلى التفكير فى استخدامها والاستفادة منها وعدم إهدارها وإعادة تصنيعها بصورة جمالية) (1) (1)

\section{هنهج البمث :}

استخدم الباحث المنهج التجريبى وهو اتجاه فلسفى يتبناه بعض العلماء ويعد الخبرة أهم مصدر للمعرفة، أى أن المعرفة المكتسبة عن طريق الحواس هى مصدر كل معرفة ، وقد أتاح لى استخدامه طرح المعالجات التشكيلية المختلفة لبناء الأشكال وصياغاتها وقرتها على التعبير الفنى ببواقى المنسوجات الملونة والمختلفة الثكل والوزن والنوع والمتخلفة عن العمليات الإنتاجية المختلفة . 
1 - إعادة إستخدام بواقى المنسوجات " من غزول واقمشة مختلفة الخامات والتراكيب البنائية وكنلك الصباغ بمختلف فصائلها " باعتبارها أحد مواد أو خامات النفايات الصلبة التى تعمل على تلوث البيئة . r - إعمال الفكر لاى الارسين تجاه المشكلة . r - المزاوجة بين فن التصوير ويواقى المنسوجات المختلفة فى الثكل والوزن والنوع فى إنتاج أعمال فنية جليدة بطريقة مبتكرة .

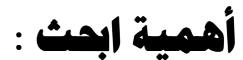

ا - المحافظة على البيئة من النفايات والعمل على التقليل منها إلى حد ما . r- الاتجاه نحو إقتصاديات التصميم حيث توافر خامة التشكيل . r- يبرز إمكاتية توظيف الأعمال القتية المنتجة من إعادة إستخدام بواقى المنسوجات المختلفة الشكل والوزن والنوع بإقامة صناعات حرفية صغيرة تساعد على المساهمة فى حل مشكلة البطالة .

\section{مدود البمث :}

تتجه الدراسة تجاه التشكيل الجمالى الخاص بالأعمال القنية ذات البعدين بإعادة إستخدام بواقى المنسوجات من غزول وأقمشة ملونة مختلفة الأنواع . وزمن إجراء البحث فصل دراسى واحد هو الفصل الدراسى الثانى من العام

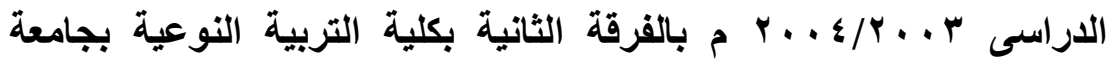
المنصورة ، وعينة الدراسة تم إختيار ها بشكل عشوائى من المجموعات التى

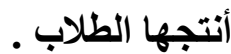


إن تقنية القص والطى ثم اللصث والتثبيت تقنية بسيطة تستخدم فيها بواقى المنسوجات المختلفة الثكل واللون والنوع والملمس بالإضافة إلى بعض المواد اللاصقة ، كما أنها تستخدم أدوات بسيطة مثل الإبرة الوبرية والإبرة العادية وذلك كوسيلة تعبيرية لإحداث وتثبيت الزخرفة ، كما تستخدم أدوات بسيطة للقطع كالقواطع بمقاساتها المختلفة أو المقصات بجانب إمكانية إستخدام القطع اليدوى وماله تأثير إلا أنها تقتية تتداخل أو تتفق مع تقنيات فنون كثيرة فى إستخدامها بواقى المنسوجات مثل التقتيات التالية:

\section{" collage" 1}

فن التجميع أو التلصيق أو ما يسمى بفنون الترويق أو الترديم كما تسميه الموسوعة العربية العالمية والبناء التثكيلى فى هذا البحث يقترب فى الوقت نفسه فى صياغة بعض الأعمال من أعمال القص واللصث أى ( الكولاج ) لكنها تختلف عنها فى الخامة المستخدمة حيث تتكون من قصاصات الأقمشة المختلفة الأنواع والأوزان والملامس بينما فن الكولاج يستخدم قصاصات الأوراق الملونة المتعددة المساحات والأثكال . وهذا الأسلوب رغم طرفته وأصالته فإن جذوره فى الفن الحديث تمتد إلى مأى بداية القرن العشرين أى عام r 19 1 عندما ظهرت المدرسة التكعبية التى استخدمت قصاصات الجرائد والمجلات فى عالم الرسم والتلوين بالإضافة إلى نشارة الخشب وقليل من الرمل وقصاصات رفيعة من اللائن البلاستيكية وتبدو هذه العناصر كعناصر مكملة للتكوين القنى العام للوحة بإضافة مزيداً من التنوع فى ملامس السطح الأمر الأى يجعل المشاهد يحس برغبة لتلمس هذه الأشياء(؟) وسمى هذا التداخل بين خامات التكوين التقليدية وهذه الأصناف المستخدمة ( بفن الكولاج ) وقد بدأت مسيرة هذا التهجين على يد كل من جورج بارك ،خوان جريس وبابلو بيكاسو (· (') 
اعترض النقاد على إقحام هذه العناصر فى ذلك الوقت فى عالم الرسم لكن مع مرور الزمن إعتاد المشاهدون هذا التقابل والصراع بين مختلف الخامات على سطح الأعمال الفنية فتغيرت المفاهيم المتعلقة بخامة العمل القنى بل وأصبح تغيير الخامات وتعديلها من مصادر فخر القنانين المعاصرين وذلك مع إنتشار فكرة ضرورة التجديد والتغيير المستمر فى اشكال الفن وخاماته ، وأصبح هذا التغيير هدفاً بعد أن كان وسيلة للتعبير عن المشاعر وطرح

(القضايا(")

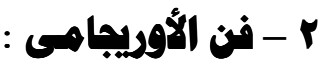

وهو أسلوب ظهر فى القرن العشرين وهو فن يابانى يتفق مع تقتية القص واللصق حيث أن الخامة الأساسية له هى الورق الملون إلا أن فن الأوريجامى لم يقتصر على الورق بل إمتد الى الخامات اللينة الناعمة مثل بقايا الأقمشة الملونة كما فى البناء التشكيلى لبعض الأعمال التطبيقية لهذا البحث ، وتعتمد التهل تقنية هذا الفن على الثثى والطى " القصات المبرومة " مع التثبيت ليصور أثكالاً طبيعية مثل الطيور والأزهار والأسماك( ·') ، وعند البناء بهذا الأسلوب يتم التأمل فى التكوين والتحقق عدة مرات لإستبدال قطع النسيج والقماش بقطع أخرى تختلف عنها فى اللون أو الملمس أو المساحة فهى تماثل لمسات الفرشاة أما القصات وبقايا المنسوجات المختلفة الألوان فهى تمثل فى حـ ذاتها ( بالتة ) الألوان للقنان حيث يختار منها ما يناسب الموضوع اول او التصميم قإذا إكتمل بناء العمل الفنى بهذا الأسلوب فإنه يثبه الفسيفساء او الموزاييك لكنه يختلف عنه فى الخامة المستخدمة ، فالفسيفساء خاماتها الأحجار أو القطع الخزفية الملونة بينما فى هذا البناء يستخدم بقايا المنسوجات والأقمشة ( المبرومة ) مع التبيت ، ويعتبر هذا البناء فى اللوحة القنية وإن جاز تسميته ( بالفسيفساء القماثية ) من الأساليب البنائية فى الفن التثكيلى الحديث وهذا الاتجاه يمثل تمرداً على اللوحة الزيتية أو اللوحة التى ترسم على حامل الرسم لتحل مكانها أعمال فنية لها نفس قيمتها وقادرة 
على آداء نفس دورها فى المجتمع ، إنها مساهمة إيجابية فى إعادة الإحترام

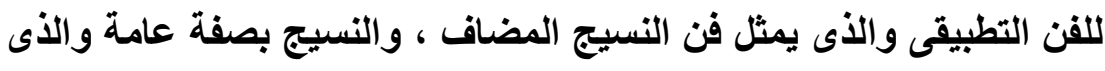
يمثل أحد فروعه التى أهلها الفنانون المعاصرون(؛) لئن

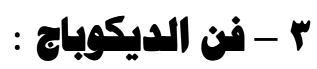

فن إستخدام القصاصات الورقية فى تزيين الأثاث وملحقاته وكذلك اللوحات المنقوشة إلا أنه قد تستخدم خامات ليتة مثل بواقى المنسوجات والأقمشة فى التزيين ويظهر الثكل التهائى فى منظره وملمسه صقيلاً لامعاً ويتم التثبيت عن طريق اللصق أو التطريز ، وكلمة ( ديكوباج ) فرنسية الأصل مشتقة من كلمة ( ديكوبيز ) ومعناها يقص (·) (1)

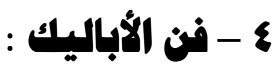

وهو فن التطريز باسلوب النسيج المضاف ، وهو عبارة عن الزخرفة ببقايا أقششة مخالفة للقماش المراد تطريزه أو نفس القماش الأصلى ويعرف هذا النوع من الفنون باسم ( الخيامية ) والأى يتميز بزخارفه النباتية المحورة والهندسية الإسلامية ، وهذا يتضح فى حالة إستخدام قطعة نسيج مضافة وتكون صغيرة الحجم مخيطة بجاتب بعضها فإنها تعرف باسم الفسيفساء كما ذكر سابقًاً .

وقد استوحى المصمم قى العصر الحديث يعض المعالجات التشكيلية المستحدثة من هذا الأسلوب لتجميل سطح العمل القنى ، وكذلك إضافة بعض الأساليب القنية والخامات المتنوعة مع غرز التطريز المختلفة كحول تثرى

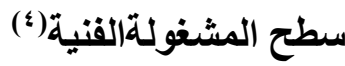

- التطريز بأسلوب التضريب " الاحاف " 
وهو من الأساليب القديمة التى تعطى معالجات تثكيلية متنوعة على سطح العمل القنى وذلك بواسطة غرز التطريز المختلفة وغالباً ما يستعمل فى هذا الأسلوب خيط من نقس لون النسيج أو مختلف عنه ويتم ذلك عن طريق عدة طبقات من التسيج بداخلهم مادة حشو ناعمة مثل بواقى القطن أو الصوف بأنواعه أو الخيوط السميكة ، وتمر إبرة الخياطة من خلال هذه الطبقات عند تتفيذ الزخرفة على سطح العمل القنى بغرز التطريز فى أشكال طولية وعرضية مختلفة ، وقد تطور هذا الأسلوب نتيجة إستخدام مواد وخامات مستحدثة مثل الحرير وغيرها من الخامات التى تعطى ملامس ناعمة على هلى سطح العمل الفنى . ملن. ويتم عمل أسلوب التجسيم بالحشو فى أجزاء محددة فى التصميم المراد تنقيذه على سطح العمل القنى وذلك بعد غرز التطريز على أطراف القماش أولاً ثم تبطن بغزل القطن أو الصوف أو أى بواقى نسيجية عن طريق فتحة فى الجزء المراد إبرازه ، كما توجد طريقة أخرى للتعبير الفتى بأسلوب التجسيم اللين فى طريقة التجزئة والتى تتم عن طريق تبطين وحشو قطع من القماش ببواقى الغزول المختلفة النوع ثم إضافتها بغز التطريز أو الحياكة . ويعتمد أسلوب التجسيم اللين على الخامات والمواد التى تعطى تأثيرات على سطحه مثل الضوء والظل حيث يعتبر النسيج الأملس ( الساتان ) والقطيفة والحرير والأقمة الصناعية الرقيقة مثل النايلون من الأقمشة المناسبة لهذا الأسلوب حيث تحتوى على درجات الألوان المضيئة والمعتمة التى تعطى لهذا الأسلوب خصائصه القنية وتميزه عن غيره من الأساليب القنية. ويتم إثراء سطح العمل الفنى المنفذ بأسلوب التجسيم اللين بمثل أسلوب الخيامية وبإضافة الشرائط الملونة بالخيوط وإضافة غرز التطريز المختلفة مع الخامات الأخرى وأيضاً عن طريق التفريغ والإضافة ، كما يمكن إضافة

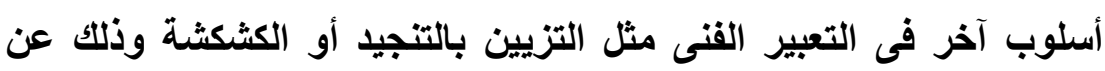


طريق غرز التطريز المتنوعة التى تكون ثنيات وكثكشة وطيات فى نسيج الأقمشة التى تتميز بالليونة مثل القطن والكتان والصوف وغيرها من الخامات ، وفى بعض الأحيان تتجمل بأساليب الطباعة اليدوية والرسم بالأصباغ والرش برزاز الألوان وغيرها من المعالجات التشكيلية المستحثثة التى تثرى سطح الأعمال الفنية بأساليب متنوعة مما يجعل المشاهد يحس برغبة لتلمس هذه الأشياء .

هذا وتستخدم بعض الاتجاهات القتية فى العصر الحديث تقتية القص وتتعدد السمات والأنماط والأساليب والتى يبدو من خلالها طرق الوصل بالحياكة

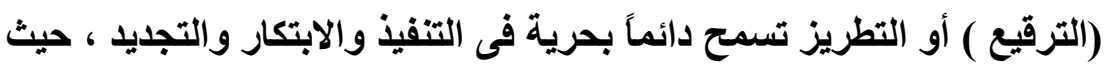
يمكن استخدام بعض هذه القصاصات على أطر اف الستائر أو مفارش المناضد وحول أسفل الجواكت والجيبات وبطول الأكتاف ونهاية الأكمام وأسفل الفساتين والبلوزات أو الملابس التى تلبس على الجزء الأعلى من الجسم وكذلك الأثاث والتتجيد وذلك باستخدام المربعات والمستطيلات باحجام مختلفة أو أى اشكال هندسية أخرى(؛) وإستخدام بقايا المنسوجات الملونة فى صياغة ويناء بعض الأعمال القنية كالمدرسة التكعيبية باعتبار هذه القصاصات أو بقايا المنسوجات كعناصر مكملة للتكوين الفنى العام للوحة ، بجاتب التنوع فى الملابس والتأثيرات الخاصة ، وقد استخدمته الدادية وهى حركة فنية إحتجاجية تقاوم المفاهيم القنية القديمة ويتميز الفن فيها بنوع من الهزل والتجريد البالغ(ه) . وكذلك المدرسة الوحسية التى استخدمت هذه التقنية ـ خاصة فى أعمال هنرى ماتيس بأسلوب يعبر عن عبقريته عند مقارنته بما أنتجه التكعبيون لما

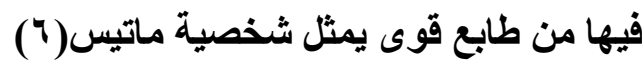
وعلى ذلك فالمقصود من إستخدام بقايا الأقشة " المختلفة التراكيب البنائية مثل السادة ، المبارد ، الأطالس والوبرة وكذلك الأقمشة الغير منسوجة بالإضافة إلى أقشة التريكو " هو التجريب الأى يتميز بالنشاط الابتكارى 
الأى يساعد على نمو التفكير والآداء المبتكر والطلاقة فى التثكيل ، حيث يعتبر التجريب أكثر الكلمات استخداماً فى التثاط التربوى والتربية القنية بخاصة ،إذ توصل إليه علماء التربية الفنية كمدخل علمى بالنشاط الابتكارى فى ضوء التقدم العلمى والمنهج القياسى الأى أسهم فى التفاعل بين العلم

والفن(')

وتأليف قطع الأقمشة المختلفة مع بعضها البعض يعطى نقطة بداية جيدة لعمل فنى مبتكر حيث يعتبر التجريب فى المشغولة الفنية منهج للفكر يقدم بدائل للحلول المختلفة فى صورة جديدة تتضمن دلالات ومعنى غير مألوف ، كما أنه الأسلوب الأى يوضح ويعرف الجوانب الجمالية المختلفة للموضوع

والتجديد فى العمل القنى يتم من خلال ممارسة الأسلوب التجريبى حيث تكون الأصالة محور الإبداع والابتكار وحجر الزاوية فى الناتج الابتكارى فى العمل القنى فآداء بعض التظيمات الحركية فى التصميم المسبق للعمل القنى وخاصة بين الأشكال والمساحات كالتبادل والتجميع والتظيم المرتبط ، والتجميع والتنظيم بالحذف والإضافة وغيرها بهدف الكشف عن مظاهر وكيفيات لها دلالات جليدة مستحدثة من خلال روئة غير مألوفة للعلاقات الأساسية لشكل العمل القنى وإيجاد التآلف بين الألوان والأشكال والخطوط

والمساحات فى وحدة كلية مترابطة (9)

\section{إن فن إبتفدام بقايا الأقمشة يهب أن يتم على أسس هى :}

1 ـ الاهتمام بالأبعاد الخاصة بالعمل القنى الذى يتم تنفيذه ومدى ملائمته

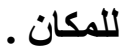


r - الاهتمام بالألوان والخامات المستخدمة .

r - الاهتمام بالتصميم الأى سيتم تتفيذه والعمل على التطوير والتجديد فيه .

وليس من الضرورى وجود التوافق فى الألوان ولكن وجود التضاد فى أحيان كثيرة

قد يؤدى إلى إنتاج عمل جيا إذا بنى هذا الاستخدام على مراعاة الذوق الفنى والحس بالألوان ، وكذلك الخامات ليس من الضرورى أن تكون واحدة ولكن اختلاف الملمس لئس والخامة يثرى العمل ويعطيه قيمة فنية وجمالية أخرى ـ ولائ

إن استخدام بقايا الأقمشة يعطى فرصة للتجديد والابتكاروانتاج أثياء لا يمكن تكرار وجودها فى أى مكان آخر وهنا تعطى قيمة أخرى وهى قيمة التفرد فى امتلاك عمل فنى

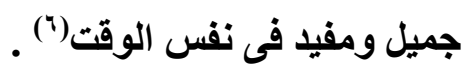

واتخذ البحث مساره من خلال محورين أساسيين ، الأول منهما يتناول عرض ومناقشة الأعمال التطبيقية التى قام بتنفيذها الطلاب سعياً إلى تحقيق أهداف البحث عن طريق اختيار عينة عشوائية من مجموعات الأعمال التى تم إنتاجها ، أما المحور الثانى فيتناول عرض أهم النتائج التى توصل إليها البحث بالإضافة إلى التوصيات .

\section{المهور الأول :}

فى اللقاءات الأولى مع الطلاب تم طرح الإطار النظرى للمقرر الأى يتناول تعريف الفن ودوره وأهميته فى حياتنا المعاصرة ، ومن ثم التعريف بعناصر ومواصفات

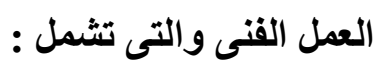

أ ـ الأرضية أوالخلفية . ب الأقمشة المستخدمة لتنفيذ التصميم

ج - أنواع الخيوط المستخدمة فى التثبيث والتطريز .

د ـ الأدوات الواجب توافرها . 
ومناقشة العلاقات التى تحكم هذه العناصر داخله ، وبعد ذلك تم طرح الإطار التطبيقى للمقرر فى صورة موضوعات مستمدة من البيئة المحلية والتراث المصرى يعالجها الطلاب تثكيلياً باستخدام بواقى المنسوجات المتخلفة من مراحل التصنيع المختلفة .

وكانت الموضوعات الاطلاوب التعبير عنها :

$$
\begin{aligned}
& 1 \text { - الريف ( مناظر من وحى الريف ) } \\
& \text { r - مناظر من وحى الطبيعة( طيور) } \\
& \text { r - مناظر من وحى الطبيعة ( أسماك ) } \\
& \text { ع - من وحى التراث الثعبى . }
\end{aligned}
$$

وبعد عرض هذه الموضوعات والتعرف على مفرداتها وعناصرها قدم الطلاب نوع من أنواع الاستجابات الفعالة المتمثلة فى مجموعة من الأعمال التى قدمت ، وعن طريق التوجيه الفردى والجماعى وعرض النتائج التى يتم التوصل إليها تباعاً وإعادة الصياغة مرة ومرات تمكن للطلاب من إنتاج عدة اعمال فنية نعرض عينة منها تم اختيار ها عشوائياً من خلال أربع مجموعات هى كالتالى :

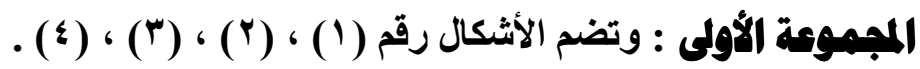
الموضوع : مناظر من وحى الريف .. مقاس الأعمال • •× • سم وهنا يتبادر لنا عدة أسئلة يطرحها البحث لمناقشة تلك الأعمال وتتمثل فيما يلى:

$$
\begin{aligned}
& 1 \text { ـ هل استطاع الطلاب التعبير عن الموضوع? } \\
& \text { r - هل مثلت الأشكال دورها فى التكوين ؟ } \\
& \text { r ـ هل استطاع الطلاب التعبير عن البيئة ؟ } \\
& \text { ع - هل تحققت الوحدة فى أعمال الطلاب ؟ } \\
& \text { • ـ هل لعب التناسب دوراً فى أعمال الطلاب ؟ }
\end{aligned}
$$


7 - الماهو دور الخط داخل أعمال الطلاب ؟

V - كيف عبر الطلاب عن العمق او المنظور ؟

^ - هل كان للإتزان دور فى أعمال الطلاب

9 - هل استطاع الطلاب استخدام بواقى المنسوجات فى بناء أعمالهم بشكل بناء

وللإجابة على هذه التساؤلات علينا ان نستعرض الأشكال ( من رقم 1 إلى ؛ ) من أشكال المجموعة الأولى وموضوعها مناظر من وحى الريف ، نرى أن الطلاب استطاعوا إعمال فكرهم بالتعبير عن الموضوع المستمد من البيئة التى يعايثونها وكاتت مفردات هذا الموضوع متمثلة فى عدة عناصر منها ماهو طبيعى من خلق الله سبحانه وتعالى كالإنسان والحيوان والأشجار والعشب والسماء وما بها من سحاب والأنهار وما بها من طيور تسبح وأسماك ، والعناصر الأخرى التى من صنع الإنسان متمثلة فى الملابس والأدوات الاستخدامية وخلافه .

هذا وقد لقيت الأثكال دورها كلاً فى مكانه ، فتواجد البيئة الزراعية فى خلفية العمل واختلاف درجات لونها مع تواجد اللون البيج واللبنى ( الزرق الفاتح ) كما فى شكل (1) ، (r) يمثل لون السماء بما فيها من سحاب وطيور باللون

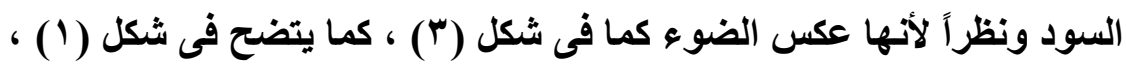
شكل (r) بعض الحيوانات ذات الألوان المتناسقة كما يتميز شكل (r) بوجود اللون الأزرق كسحاب وقد تم بنائه باسلوب الوبرة وذلك يمثل حلاً تثكيلياً يعطى العمل القنى قيمة جمالية جديدة بالإضافة إلى تقسيم أرضية مقدمة العمل بلدرجات الأخضر مع البنى والبيج .

كما يمثل شكل (ع) التهر وما به من طيور مختلفة النسب فهذا كله يمثل عمقاً يحقق المنظور فى هذه الأعمال ذات البعدين وقد لعب الخط دوراً هاماً فى تحديد المساحات أو الأشكال فى صورة خط رأسى مرة وأفقى مرة أخرى ومنحنى مرة 
ثالثة ومتعرج مرة رابعة وإثعاعى مرة خامسة ، وهذا يتضح فى تعبير الخط عن الأشكال أو الهيئات الى تتخذها بواقى الأقمشة .

هذا وترتبط أجزاء العمل فيما بينها ترابطاًعضويا وتجعله كلاً متماسكاً مما يحقق نوع من الوحدة فى العمل القنى نظراً لأنها تحتوى على نظام خاص من العلاقات يمكن إدراكه عن طريق : 1 - علاقة الأجزاء بعضها ببعض .

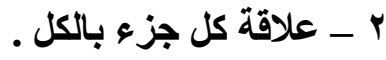
r - علاقة الكل بالكل .

أما عن النسب والتتناسب فقد طبقها الطلاب بالإحساس الفطرى التلقائى للإنشائية الجمالية عن طريق تناسب العنصر المفرد مع الثكل الكلى ، وبالترتيب المناسب لاتجاه وموقع كل عنصر من العناصر الجزئية بشكل يقترب إلى حد ما من النسب

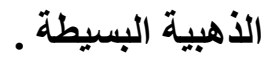

وقد تحقق التوازن وهو من الخصائص الأساسية اتى تلعب دوراً هاماً فى جماليات التكوين من خلال تنظيم علاقات الأجزاء او الأشكال فى الأعمال الفنية عن طريق تواجد الخطوط واتجاهاتها يمينا ويساراً ورأسياً وأفقياً حول محور العمل القنى فى الأشكال ( من رقم ا إلى رقم ؛ ) وعن طريق الأشكال حول محور العمل ممثلة نوعاً من الاتزان اللاشكلى وهو يمثل قيمة جمالية للأعمال بالإضافة إلى الى الى تحقيق التوازن عن طريق إستخدام اللون بشكل يؤكد توازن العمل(9) . ولتحقيق الإيقاع الذى يضفى الحيوية والديناميكية والتنويع وجماليات النسبة القائمة على التوازن داخل نظام التكوين هناك قيمة فرعية تبرز الإيقاع من خلال تكرار بعض الأشكال كما فى أشكال الأشجار والأعثاب ، ومن خلال التدرج اللونى لتقسيمات أرضية الأعمال كما يتضح فى الثكل (من رقم ا إلى رقم ب ) وأيضا يتحقق الإيقاع عن طريق التنوع فى أشكال الأشجار والأعشاب والطيور واختلاف المساحات عن بعضها ومن ثم يتحقى الإيقاع عن طريق مساحات وألوان مستمرة 
داخل هذه المجموعة مما يمثل ضرباً من الإيقاع ، قدم الثكل رقم(بّ) حلا تشكيليا للأعشاب والسماء وما بها من سحاب يختلف عما قدمه أقرانه وهذا الحل يتسم بقيم جمالية ذات بعد مهارى ، هذا ويتحقق فى شكل (ء) قيم جمالية وإبداعية تتسم بالأصالة والطلاقة والمرونة والتعبير الصادق عن البيئة الريفية وتتضح معالم هذه القيم فى إستخدام الطالب بواقى المنسوجات ذات ألوان وملامس تعبر عن طبيعة الأثجار والحيوان وغيرها من العناصر فى البيئة الريفية ، وتم اختيار لون السماء بالأزرق الفاتح والذى يتكامل مع اللون الزرق للمياه فى الجندل الصغير بالاضافة إلى اللون البيج فى الأرضية يتكامل مع اللون الخضر المستخدم فى التعبير عن عشبية الأرض وإنباتها بجوار الجندل الصغير الذى يجرى فيه المياه وتسبح فيه مجموعة من الطيور على اختلاف أشكالها ، ومن ثم يتضح من هذا العمل جرأة الطالب باستخدامه العناصر النباتية والحيوانية البيئية فى عمله ، ونضيف أن الطالب حاول فى مجموعة الحلول التثكيلية التى قدمها استخدم الشجرة كحل تثكيلى رمزى هو تمثيل لطبيعة الشجرة والخضرة بصفة عامة والتى يتعايش معها ، كما أن الحيوان فى الشكل رقم (r) قد بالغ وعنى بلراسته لأهميته ودلالته فى الاعتماد عليه فى البيئة الريفية ، وكذلك عنصر الجرة التى تحملها الفلاحة فى العمل القتى رقم(ץ) قد عالجه بشكل جيد لأهميته أيضاً فى الحفاظ على الماء الذى هو سر الحياة ولكونه أيضاً أكسير الحياه الريفية بصفة خاصة والحياة بصفة عامة كما يتضح فى أعمال المجموعة خاصة شكل I ، ب ب ، ب باستخدام بواقى

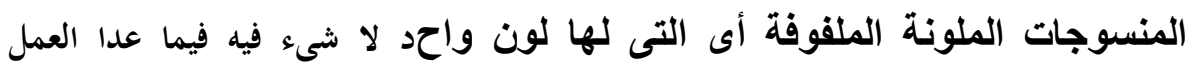

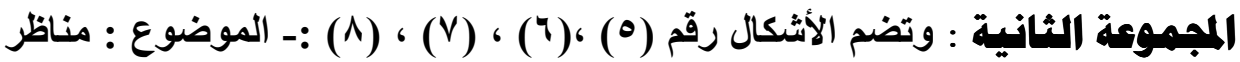
من وحى الطبيعة ( طيور ) مقاس الأعمال • هسم × • Vسم

كل عمل فنى يخضع فيه تمثيل الطبيعة ومحاكاتها للتعبير عن الاتفعالات والأحاسيس الأتية ويطلق بصفة خاصة على الفنون التى تتميز بأسلوب فطرى ويتم فيه الانطلاق والتغيير والتبديل فى العناصر أو الأشكال الطبيعية لإبرازالقيم 
الانفعالية وحلول تشكيلية أخرى ذات مضمون تعبيرى (^) ، هذا ما حققته أعمال

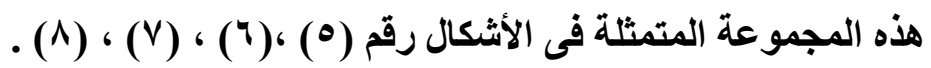
- يمثل شكل رقم (0) حلاً تشكيلياً يتسم بالبساطة يعبر عن منظر طبيعى للطيور والزهور ، فنجده من الأمام غصن زهرة يقف عليها طائر صغير مستعد للهروب ومن الخلف طائر آخر مستعداً للإتقضاض عليه فارداً جناحيه ، هذا مأرها وقد عبر اللون اللبنى عن العمق خاصة فى أرضية العمل الفنى وفى معالجته الرمزية للأثكال وعناصر العمل القنى حيث يتغير اللون كلما ابتعد عن مقدمة العمل ، هذا ونجد أنه توجد وردة كبيرة فى مقدمة العمل القنى ذات اللون الأحمر المصفر بثكل تلقائى بسيط وفى مؤخرة العمل تتناثر بعض الزهور ذات الألوان المختلفة ، وقد عبر اللون الأخضر واللون الأسود فى عدة عناصر تثكيلية ، فهو فى مؤخرة العمل يمثل الطائر الجارح وفى مقدمة العمل يعبر اللون الأخضر عن الأوراق التلى يقف عليها الطائر الصغير . - وتتضح الوحدة فى هذا العمل كقيمة جمالية من خلال تماسك العناصر الفنية وترابطها ومن خلال الأسلوب المستخدم فى الصياغة التشكيلية وعن طريث السيادة للون اللبنى والأى يمثل الخلفية الرئيسية للمنظر الطبيعى بالنسبة

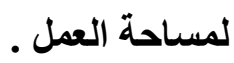
- الاتزان كقيمة جمالية نجده قد تحقق عن طريق توزيع العناصر والأثكال حول

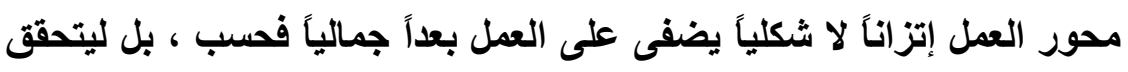
التنوع وهو القيمة الجمالية من خلال اختلاف العناصر فى الحجم أو فى الدرجة اللونية أو النوع فهناك الزهور والطيور والأغصان والأوراق وكلا له شخصيته

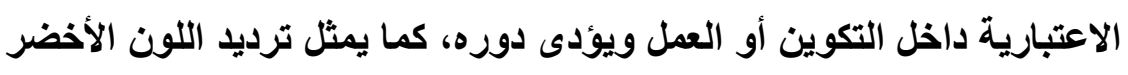
ضرباً من الإيقاع داخل العمل ويمثل اللون اللبنى ( الأزرق الفاتح ) بدرجاته وهو لون منسحب خلفية للعمل ويبرز فى المقدمة للمنظر الطبيعى الأى يظلب عليه اللون الأخضر ويحتوى ضمنياً درجة من السخونة والدفء بجانب لون

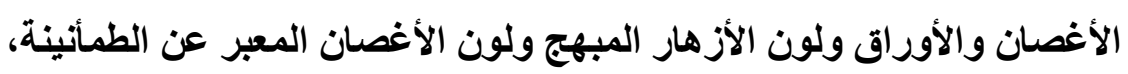


ويتحقى التباين فى تلك الأعمال نتيجة قدرة الطالب على الإدراك البصرى للفروق الكبيرة بين الأشكال والخطوط والدرجات اللونية .

أما التوافق فقد تحقق بين اللون الأخضر ودرجاته وبين اللون الأزرق ودرجاته، هذا والتقسيم الرأسى للتكوين يعطى انطباعاً ودلالة على الإيقاع والسمو والاتساع فى نفس الوقت .

- ويمثل شكل (†) معالجة تثكيلية وحلا جماليا يتسم بالطابع الزخرفى البسيط وبشكل تلقائى على الرغم من التنوع فى أشكال الطيور أو الأغصان ويتضح فى تصميم أوراق الأغصان بشكل زخرفى مع أنه تمثيل للواقع بالإضافة للزهور التى تتبثق من الخلف ثم مجموعة من أوراق الثجر والتى تبدو كمصفوفة يليها فى نهاية العمل القنى مصفوفة أخرى من أوراق الشجر لبنية اللون( أزرق فاتح ) فى تتابع ثم الخلفية البيج التى تمثل الفضاء باتساعه ، ثم يوجد فى منتصف العمل الفنى الطيور المختلفة الألوان ونظراً لأن هذا العمل فطرى الطابع ، وتعبير ذاتى من الطالب يقترب إلى حد ما من مبدأ التماثل إلا أنه تماثل لا شكلى هذا ونجد أن الطالب قد استخدم تراكيب بعض الأقمشة ليعطى انطباعاً بالظلال وليحقق البعد والعمق . - ويمثل شكل رقم (V) حلاً تشكيلياً آخر محملاً بقيم جمالية إلا أنه قد يختلف عما سبق من أعمال نظراً لأن الطالب قد استخدم فى تقنيته لهذا العمل نمطين من أنماط بواقى المنسوجات الملونة ، الأول ذات لون واحد لا يخالطها لون آخر والثانى بواقى أقمشة ذات تداخل لونى مرسوم يدوياً من الأخضر والبيج كما فى لمى بعض أوراق الغصن أو الفرع والأبيض مع الرمادى وكذللك الأخضر مع الأصفر

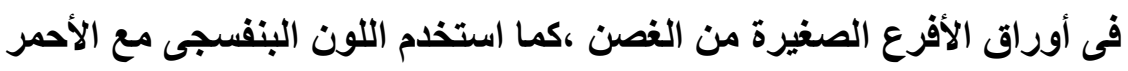
بلرجاته كما فى الزهور والتى تمثل عمق العمل وتتتوع الرمادى والأبيض مع الأزرق والبنفجى والأحمر فى أثكال الطيور هذا من جهة الخامة أما من جهة طريق الآداء والتقنية فنجد أن هذا الطالب يمتلك قرات مهارية وتحليلية عالية فهو قد استخدم طريقة القص واللصق كما فى أوراق الزهور وتقنية فن 
الأوريجامى التى تستخدم الثنى والطى فى تنفيذ عمله ، و هذا يتضح فى ثنى أو طى بواقى الأقمشة التى تعبر عن الطيور وسكونها على الأغصان وأيضا استخدم نفس تقتية فن الأوريجامى فى تصميم الزهور التى فى عمق العقى العمل الفنى باستخذام الطى والثنى مع التثبيت هذا وقد استخدم الطالب فى هذا العمل

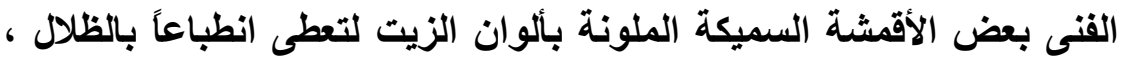

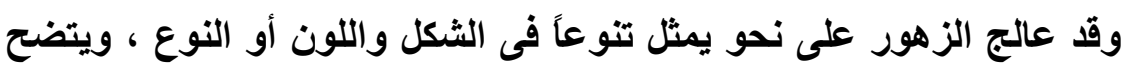

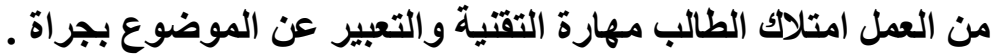
- ويمثل شكل (^) معالجة تشكيلية أخرى عن موضوع الطيور بشكل يتسم

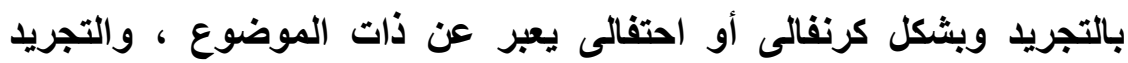
يوضح مدى نجاح الطالب فى استخلاص الجوهر من الثكل الطبيعى وعرضه فى شكل جليد بهلف الحصول على نتائج فنية عن طريق الخطو والثكل واللون حيث تتحول الأثكال الطبيعية إلى أثكال محورة تقترب من تقتية المدرسة التعبيرية التجريدية (9) ، هذا وقد عبر الطالب عن كل عناصر الموضوع بثكل

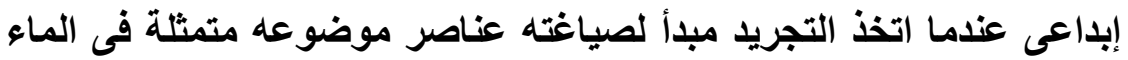
و الطائر والزهور والأعثاب الخضراء فى مقدمة الصورة ونلمس فى هذا العمل الكثير من القبيم الجمالية كالاتزان اللاشكلى للعتاصرداخل التكوين ، والوحدة العضوية كقيمة جمالية تنبع من أسلوب الصياغة وارتباط العناصر بعضها

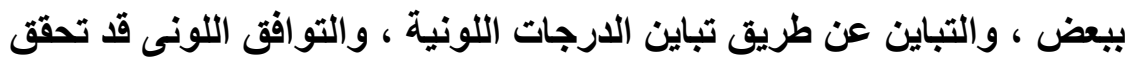
عن طريق درجات اللون الأخضر مع الأزرق فى باية ونهاية الصورة بالإضافة إلى الإيقاع الناتج عن حركة الألوان وتوزيعها داخل العمل . 
الموضوع : مناظر من وحى الطبيعة (أسماك) مقاس الأعمال • • سم × >

يمثل شكل رقم (q) تكوين من الأسماك تسبح فى قاع البحر وفى مقدمة الصورة بعض الثعب المرجانية بالإضافة إلى دوامات المياه باللون الأزرق الغامق وقد استطاع الطالب فى هذا العدل التعبير عن الحركة المتمثلة فى أوضاع السمك المختلفة ، كما استطاع أن يعبر عن المكان فى أوضاع القاع وفى المقدمة لبعض قطع الثعب المرجانية بألوانها والتى تتوافق مع لون السمك ولون المياه بزرقتها والتى ينتثر بها بعض الدومات بلونها الغامق ،

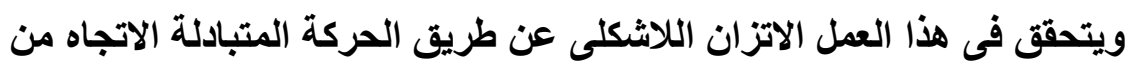
السمك والدومات المائية وقد أكلت مجموعة الثعب المرجاتية هذا النمط من الاتزان .

وقد تحقق أيضاً فى هذا العمل قيمة جمالية أخرى هى الايقاع عن طريق

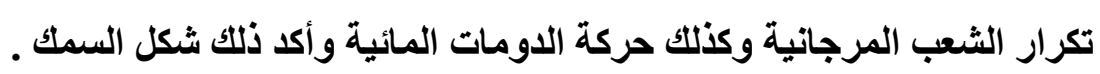
- وقد لعب التباين بين الأشكال والخلفية دوراً يتمثل فى تأكيد الأسماك باستخدام

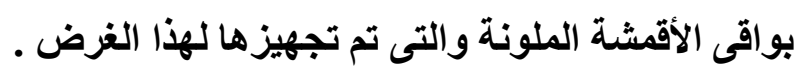

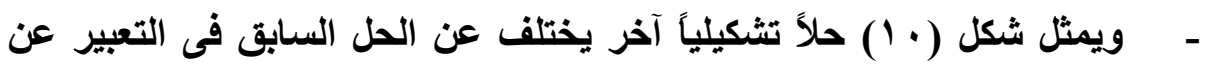
بتاء الموضوع فقد استطاع الطالب استخدام تقنية القص والتثبيت بالتطريز لبقايا الأقمشة ذات التدرج اللونى ، كما نجح فى الجمع بين الزمان والمكان

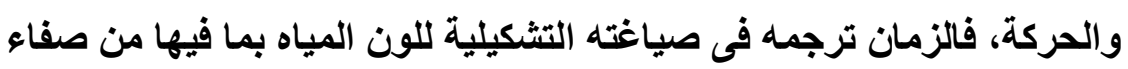
ونقاء وشفافية والتى تعطى أنطباعاً بأن هذا التوقيت فى وضع التهار حيث يظهر بوضوح تفاصيل القاع ، أما التعبير عن المكان فقد تم عن طريق صياغته لقاع البحر وما يحويه من أشكال الشعب المرجانية والنبات بأحجام وأشكال مختلفة وترجم الحركة عن طريق حركة الأسماك إلى أعلى وإلى اليمين تارة وإلى اليسار تارة أخرى ، كما أكد ذلك حركة الفقاقيع الهوائية ذات الأحجام المختلفة حيث تصعد من أسفل إلى أعلى محققة الإيقاع كقيمة جمالية ، وقد 
اقترب الطالب فى عمله من الاتزان اللا شكلى ، وتحققت فى هذا العمل الوحدة العضوية عن طريق علاقة الأشكال ببعضها البعض وعن طريق كل شكل بالكل وعمل على تاكيد هذه الوحدة توحيد اللون الذهبى للخيط المستخدم فى التثبيت بطريقة التطريز والذى يحدد كذلك الأشكال لمجموعة الأسماك واستخدم البيج بشكل سيادى ، كما أن صياغة مجموعة الأسماك بأحجام مختلفة ، وكذلك الفقاقيع الهوائية فى الخلفية تعمل على تحقيق العمق فى العمل وتعطى إحساساً بان هناك مسافة بين العناصر ، هذا ويحقق اللون الأزرق الفاتح فى الخلفية والممثل للماء بعداً آخر يؤكد العمق فى العمل أو الإحساس بالمنظور ، هذا ويؤكد الترتيب المناسب لاتجاه كل عنصر من العناصر الجزئية فى العمل بلإل بالاضافة إلى وحدة العمل قيمة التناسب كقيمة جمالية. - ويمثل شكل (1 1 ) حلاً تشكيلياً آخر لنفس الموضوع فى لقطة مقربة تجمع بين تكوين ثنائى من الأسماك فى القاع وتزينه بعض النباتات المائية بأسلوب تلخيص مبتكر يقترب من تجريد الثكل الطبيعى ويمكن توظيف هذا الكادر فى أعمال الدعاية لأحد الهرجانات التى تهتم بالبحار وما تحويه ، ويتميز هذا العمل بالتعبير القوى والصادق عن الأسماك التى على الرغم من إلغاء كل التفاصيل أو التخلص منها والتى تؤكد التجسيد ، وأهم القيم الجمالية التى بنى عليها هذا العمل القيمة التعبيرية والحركة بالإضافة إلى التلخيص والتباين ـ - ويمثُل شكل (r I ) حلًا إبداعيا آخر لذات الموضوع فهو لمنظر

طبيعى مكون من مجموعة من الأسماك وكأنها تمثيل لإحتفالية يتضح فيها البيئة البحرية عن طريق تصوير الأعماق وما تحويه من أنواع مختلفة من الأسماك والأعشاب كما يبرهن ذلك ويؤكده تصوير حركة الفقاقيع المتصاعدة والتى تخرج من فم الأسماك ويتضح من هذا العمل الاستخدام الأمثل لبقايا الأقمشة الملونة خاصة فى لون الأسماك المختلفة النوع والحركة مما يعطى ذلك إحساساً وكأنها فى احتفالية وحققت نوعا من الإيقاع اللونى الذى يتوافق لقو التى مع هذا الوضع ، وقد حققت حركة الأسماك فى مقدمة العمل ضرباً آخر من 
الإيقاع ، والتباين الناتج من تباين لون الأسماك المختلفة أكد وجودهم وعمل على لفت النظر وجذب الانتباه إلى العمل المشحون بالتعبيرية والاتفعال .

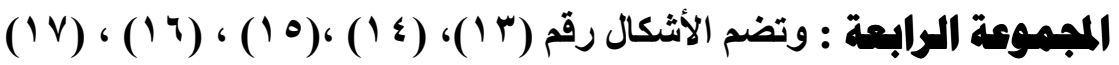

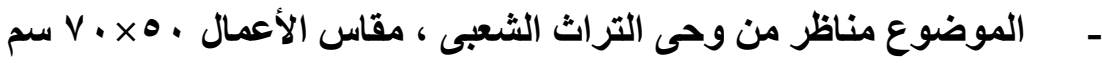
الفن الثعبى هو الفن الذى ابتدعته الجماهير أى أفراد الثعب أو مايسمونه " الفولكلور " وهى كلمة من أصل المانى وتستعمل كما هى فى معظم لغات العالم ، تزين ماتتطلبه حياتـا اليومية من أدوات أو ماتتطلبه عقائدها الفطرية او أفراحها أو مناسباتها على اختلاف غاياتها ومظاهرها ـ فالفن الشعبى فن جمالى لا يعرف الفردية لأنه فن الجماهير العريضة والفنان الشعبى لا يتناول سوى الموضوعات التى يعرفها معرفة متوارثة وتتجاوب مع احتياجات المجتمع الذى يعيش فيه ، فالرسم عند الفنان الثعبى يمثل واقعاً عقلياً أكثر مما يمثل واقعاً بصرياً ، كما أنه يرسم الأشياء المرئية وغير المرئية مادام غير المرئى معروف كما أن الفن الشعبى لا يعترف بقواعد المنظور .

ومصر غنية بفنونها الثعبية التى تتبع من صميم الحياة الثعبية منها مايرسمه القنان الثعبى على جدران المعابد ودور العبادة وكذلك التصوير الحائطى وبخاصة ماكان معبراً عن سفر المحمل أو عودته وحوله الجماهيرالفرحة بهاه ، وفى رسم الوشم والعرائس المتعددة الأشكال والزخارف والعصان وعليه الفارس وفوانيس

$$
\text { رمضان ... الخ }
$$

كما ان حياة القنان الشعبى فى حد ذاتها تعتمد على الروئية والتأمل اليومى لأحوال كل ما يحيط به ، حيث أن الفكرة الأساسية تقوم على تذوق الجمال المحيط بالجماعة والاستمتاع به فى أوسع صورة ومجالاته فى حياتهم اليومية ، وكذلك التعبير عن أحاسيسهم وآمالهم وعاداتهم وتقاليدهم تعبيراً حراً مطلقاً ، ولهذا نجد أن الفن الثعبى تميز باستخدام الوحات المحلية وكذلك الخامات المستمدة من 
وقد عالج الطلاب بعض هذه الموضوعات(ه) ، فيمثل شكل رقم(ب I ) معالجة

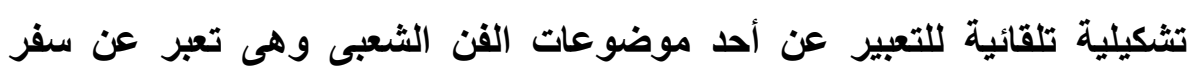

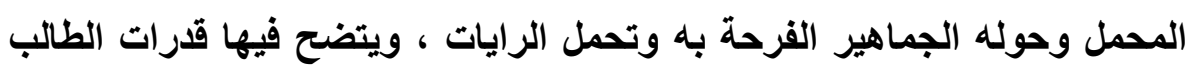

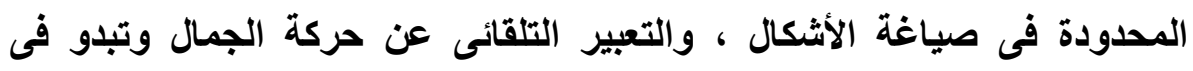

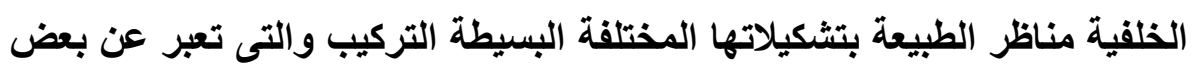

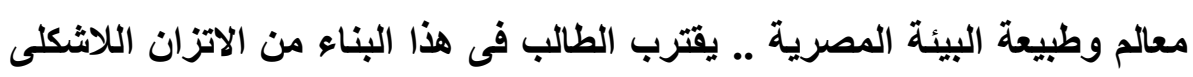
وهو قيمة جمالية ، كما نجده اعتمد على تدفق انفعالاته وفرحته وعلى تلقائية

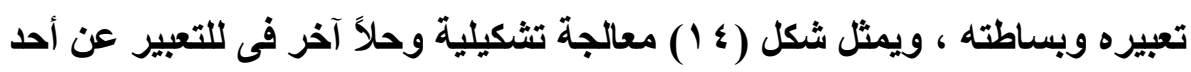

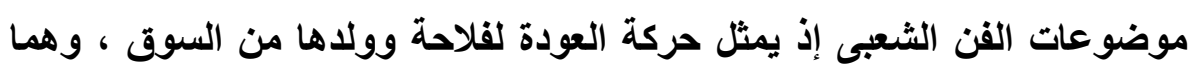

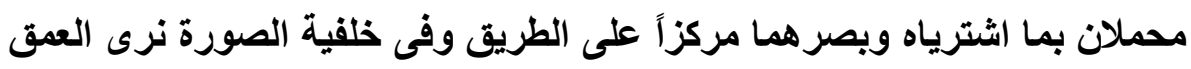

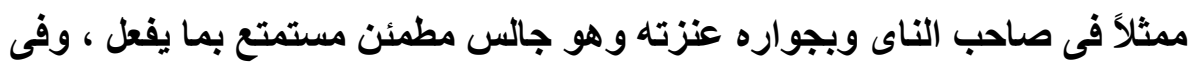

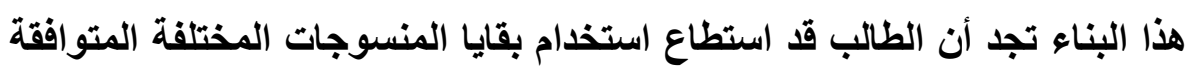

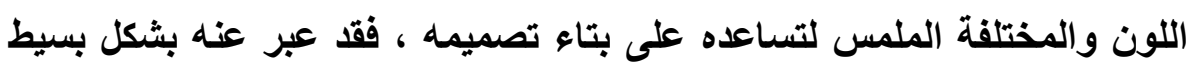
وتلقائى يتسم بالتجريدية باعداً عن القواعد المدروسة حيث نجده المباء انتقل بالأثكال الطبيعية من خلال التجريدية إلى أثكالها الجوهرية ويتضح ذلك من خلاعل البناء. ويمثل شكل (10) حلاً تثكيلياً للتعبير عن أحد موضوعات الفن الثعبى وهى

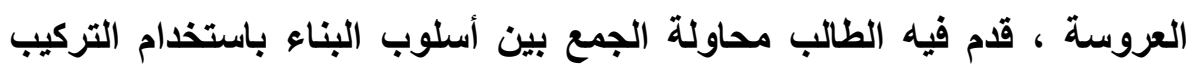

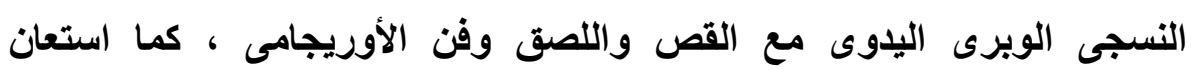

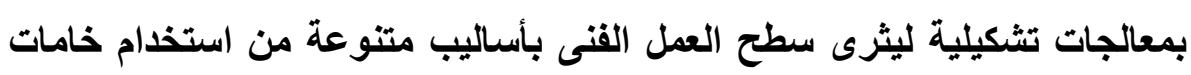

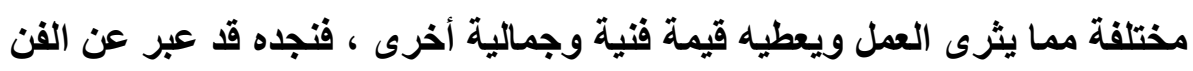

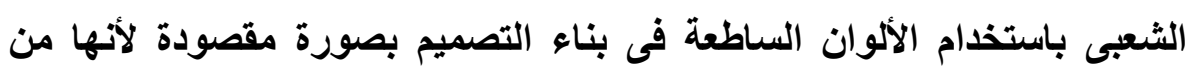
سماته ، كما نجد استخدام خامات متنوعة وتم حشوها بألياف نسيجية لإظهار

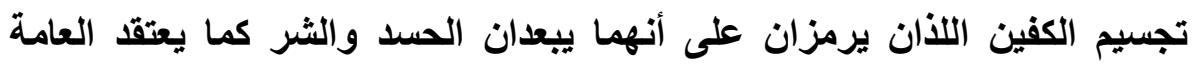

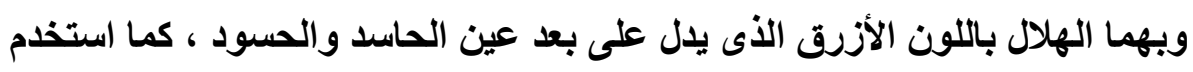

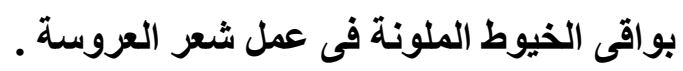


ونجد أن بناء التصميم فى هذا العمل قد إعتمد على عنصرين : الأول الوحدات الهندسية البسيطة ويتضح ذلك فى عمل الإطار ، والعامل الثانى هى الزخارف

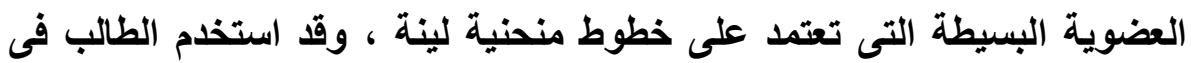
بناء عمله بقايا الأقمشة والمنسوجات الملونة بالألوان الأحمر والأصفر والأزرق والذهبى وهى من سمات ودلائل الفن الثعبى والتعبيز عن التصميم بشكل تلقائى تتأكد فيه فطرية التعبير والتناول ، ونجد أنه تحرر من الواقع المألوف واعتمد على ولى الفكرة والرمز أكثر من الصورة المتكاملة. .

ويمثل شكل (7 (1) حلاً تشكيلياً آخر للتعبير عن أحد الموضوعات الخاصة بالفن الشعبى وهو حرفة ممن الحرف الثعبية ( بائع العرقسوس ) ، فهذه المعالجة اتسمت إلى حد ما بالنضج والوضوح ويظهر ذلك فى توضيح الأشياء وإبرازها وإظهار ها بكل تفاصيلها ، فقد استطاع الطالب فى هذا البناء التعبير عن الموضوع تمثيلاً رمزياً للواقع فمثل السيدة وهى تثنترى من البائع مرتدية الجلباب الشعبى ذى لى الألوان الساخنة المتباينة وهى تمد يدها بحركة تلال على الوقار وكذلك حركات البائع وهو يمد يده إليها بالإناء فى حالة رضا وطمأنينة بالإضافة إلى أنه إستطاع أيضاً التعبير عن العمق أو المنظور عن طريق تصغير المبانى الإسلامية والمتمثلة فى القباب والمآذن كلما إبتعدنا عن مقدمة العمل وعن طريق التدرج اللونى للأبنية فى خلفية الصورة وبالتالى قدم الطالب محاولة للجمع بين الأشكال المتعددة الأبعاد كما نجح الطالب فى الجمع بين الزمان والمكان والحركة ، فالزمان ترجمه فى صياغته التشكيلية للسماء بما فيها من صفاء ونقاء وذلك يعطى انطباعاً بأن التوقيت هو النصف الثانى من النهار ، أما التعبير عن المكان فقد تم عن طريق صياغته لأحد المبانى الاسلامية بثكل زخرفى يحتوى على فناء واسع أمامه ، وترجم الحركة عن طريق رفع الأيدى للسيدة وخفضها من البائع بالإضافة إلى حركة قدميه محققاً الإيقاع كقيمة جمالية . هذا وقد حقق التناسب فى العمل كقيمة جمالية عن طريق علاقة الأشكال ببعضها ، وعن طريق التقسيم العرضى لمساحة العمل بنسب متباينة وباستخدامه الترديد 
اللونى للأثكال داخل العمل يتحقق الإيقاع كبعد جمالى ، ويتضح أيضاً الاتزان

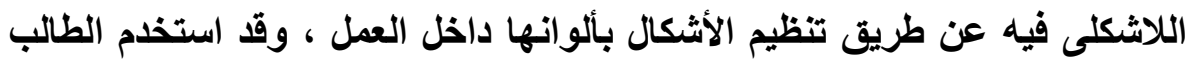

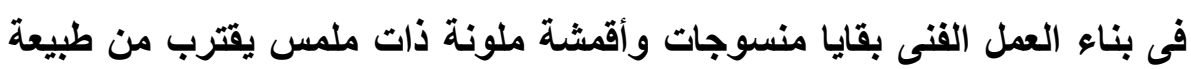
التصميم - (التصميم

- ويمثل شكل (IV) حلاً تثكيلياً جدياً للتعبير عن وحدة التراث المصرى بصفة

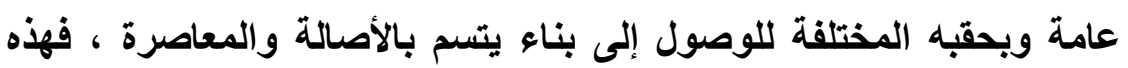
المعالجة اتسمت إلى حد كبير بالنضج الفنى إذ استطاع لطلاب فيه التعبير عن الحضارة الفرعونية بعظتها وشموخها متمثلة فى التمثال الفرعونى مع مفتاح الحياة والثمس الفرعونية وبعض زهور اللوتس وعن الحضارة الإسلامية بما

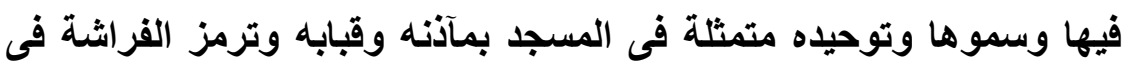

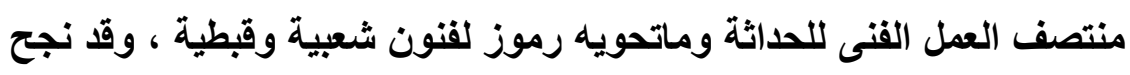

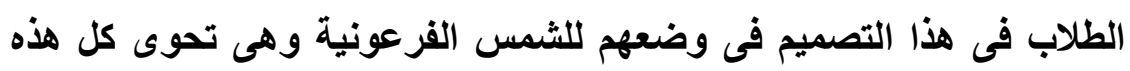

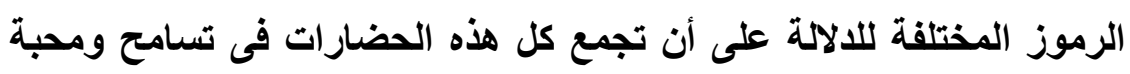

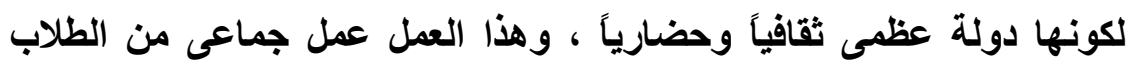

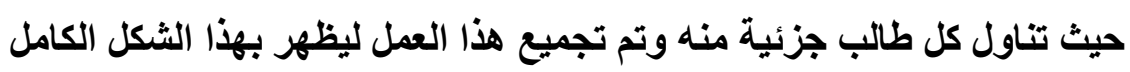

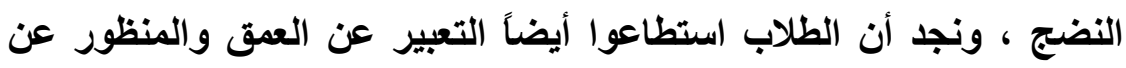
طريق التدرج اللونى للعناصر المجسمة فيتضح فى هذا التصنيف التصميم التكوين

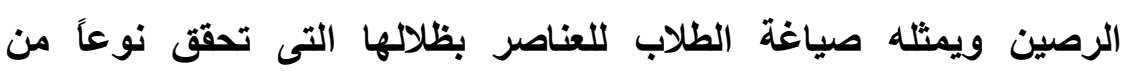

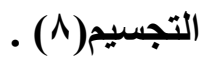

هذا ونجد أن الطلاب قد حققوا التناسب فى العمل كقيمة جمالية عن طريق

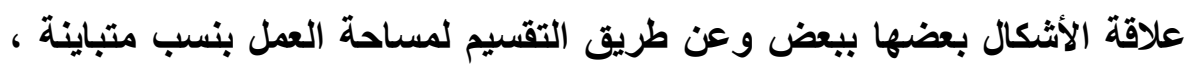
كما استخدموا الترديد اللونى للأثكال داخل العمل الذى يعقق الايقاع كبعد بمالى(") . ويتضح الاتزان عن طريق تنظيم الأشكال بألوانها داخل العمل الفنى هذا وقد

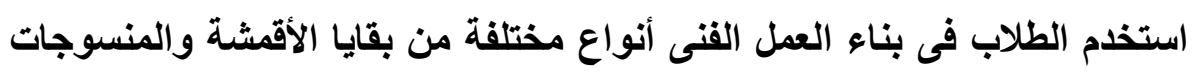
ذات ملامس تعطى التصميم قيمة فنية أكبر ولتزيده ثراءاً . 
بعد عرض ومناقشة الأعمال التطبيقية التى قام الطلاب بنتفيذها باستخدام بقايا الأقمشة والمنسوجات الملونة كأحد المخلفات الصلبة الناتجة عن عمليات التصنيع

المختلفة والتى تؤدى إلى تلوث البيئة خرجت الدراسة التجريبية بالنتائج التالية : 1 - إن التعبير الفردى عن الاتفعالات فى الفن يعطى النشىع فرصة لإظهار بعض ردود الأفعال فى ربط أنفسهم بالبيئة .

r _ أمكن إستخدام بقايا المنسوجات والأقمشة الملونة باعتبارها أحد النفايات الصلبة المتخلفة عن عمليات التصنيع المختلفة قام بها الطلاب بإعمال فكرهم فى بناء

$$
\text { أعمال فنية جديدة وبطريقة مبتكرة . }
$$

r - العمل على التقليل من كمية النفايات الصلبة بالتخلص أو الإقلال من أحد مكوناتها عن طريق إعادة الاستخدام . ع - إن إعادة إستخدام بقايا المتسوجات كأحد النفايات الصلبة يعد بعداً اقتصادياً فى عملية التصميم نظراً لتوافر خامة التشكيل وقلة التكاليف فى إنتاج مثل هذه الأعمال .

ه - يمكن توظيف تلك الأعمال القنية كأصول طباعية فى مجال الأعمال القنية . צ - إتضح فى أعمال الطلاب الفروق الفردية بين أعمالهم عن طريق طرح المعالجات التثكيلية المختلفة حول الموضوع الواحد على اختلاف بيئاتهم .

V - تمكن بعض الطلاب من التعبير عن الحركة والزمان والمكان فى أعمالهم المطروحة . 
^ - على الرغم من أن قدرات الطلاب فى هذه المرحلة محدودة إلا أن عامل الخبرة الفنية غير المباشرة جعل البعض منهم يحقق بعض مقومات العملية الإبداعية من

$$
\text { أصالة وطلاقة ومرونة . }
$$

9 - مع تلقائية التناول والتعبير القتى البسيط فى صياغة الأشكال الرمزية أمكن توظيف اللون لكى يؤدى دوره داخل العمل الفنى عن طريق دلالته وإدراك العلاقات

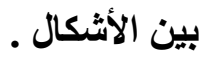

. 1 - تقيد تجارب هذه التقنية فى تطوير التفكير الإبداعى لاى الطلاب وفى الوقت نفسه تفتح الباب لاراسة وسائل ووسائط جديدة فى مجال التعبير الفنى .

\section{ثانيا التوصيات :}

1 - يجب المساهمة فى إيجاد حلول تساعد فى التخلص من التلوث البيئى كمطلب

$$
\text { حضارى وقومى وعالمى . }
$$

r - تثجيع الطلاب على البحث عن جمال التكوين فى الطبيعة ومعرفة العناصر الأساسية له من خطوط وأشكال وألوان وغير ها بالوسائط المتاحة .

r - بقايا المنسوجات والأقمشة مادة مألوفة إلى درجة نظن معها أننا تعرف عنها كل إمكانياتها فهى سهلة طيعة فى معالجتها لا تعوق التعبير ، وفى التصميم يجب على

الطالب أن يطور قدرته الخاصة بفهم المادة وأن يخرج عن طريقها ما يتخيله . ع - إقامة صناعات صغيرة لإثراء التراث الفنى باستخدام بقايا الأقشة مساهمة فى حل مشكلة البطالة. 


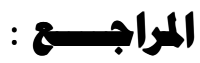

1 - لطفى محمد زكى (دكتور) \& محمود النبوى الشال (دكتور) - طرق تدريس التربية الفنية ـ الجهاز المركزى للكتب الجامعية والمدرسية والوسائل التعليمية

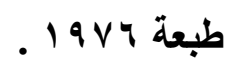

r - الإنسان والبيئة ـ مرجع فى العلوم البيئية للتعليم العالى والجامعى - المنظمة

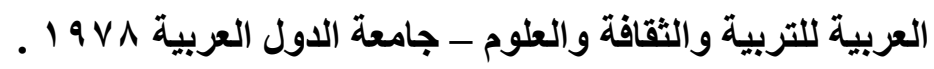
r - روبرت جيلان سكوت - ترجمة عبد القادر محمد إبراهيم ، محمد محمد يوسف -

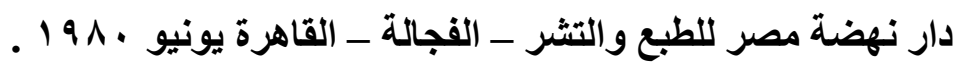

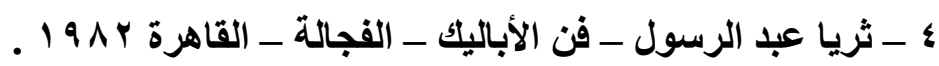

هـ أبو صالح أحمد الألفى (دكتور) \& فؤاد محمود حسنى (دكتور) - التذوق القنى وتاريخ الفن - الجهاز المركزى للكتب الجامعية والمدرسية والوسائل التعليمية $.19 \wedge \wedge$

4 - هدى أحمد زكى ـ المنهج التجريبى فى التصوير الحديث ـ دار المعارف ـ القاهرة .1994

V - محمد عبد القادر - البيئة - مشاكلها وقضاياها وحمايتها من التلوث - مكتبة بن

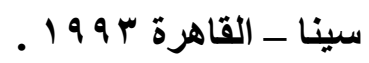

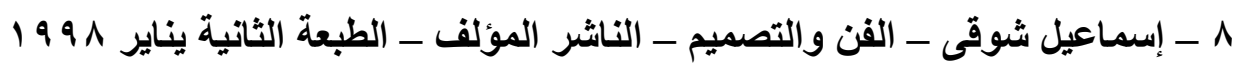

9 - محسن محمد عطية (دكتور) - القيم الجمالية فى الفنون التشكيلية ـ دار الفكر

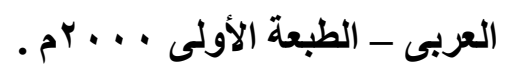

ـ 1 - محمد محمود أحمد شحاته (دكتور) - بحث مقدم إلى المؤتمر العلمى السابع نحو بيئة نظيفة ـ كلية القنون التطبيقية جامعة حلوان نوفمبر م. . . . . . 
دكتور / أشرف عبد الفتاح مصطفى سعيدء

شهرت الآونة الأخيرة إهتماماً متزايداً للحفاظ على البيئة وصحة الإنسان ، فمعظ البلاد الصناعية الكبرى - ومصر - أصدرت قوانين صارمة لحماية البيئة وظهرت العديد من الاراسات العلمية تبحث فى كيفية مواجهة إختلال التوازن البيئى لكوكب الرض ، ومن هنا تبرز أهمية الأبحاث التطبيقية حول الاستفادة من نفايات ويقايا المنسوجات المتخلفة عن مراحل التشغيل المختلفة من مصانع المنسوجات ، وبدلا من أن تكون عباً على البيئة حيث تمثل هذه النفايات مشكلة خطيرة لأن معظم الطرق التى تستخدم للتخلص منها تتسبب فى تدمير البيئة ، لهذا يعتبر هذا البحث التطبيقى الذى يعتمد على التجريب والتحليل كأحد الحلول حيث يمكن الاستفادة منها فى عملية التعبير والإبداع القنى عن طريث تقنيات وأساليب مختلفة .

فتأليف قطع الأقمشة والمنسوجات المختلفة مع بعضها البعض يعطى نقطة بداية جيدة لعمل فنى مبتكر كما تعطى فرصة للتجديا وبالتالى إنتاج أشياء لا يمكن تكرار وجودها فى أى مكان آخر وهنا تعطى قيمة أخرى وهى قيمة التقرد فى إمتلاك عمل فنى جميل ومفيد فى نفس الوقت ، فالإبداع فى التعبير الفنى ليس له حدود فى الابتكار

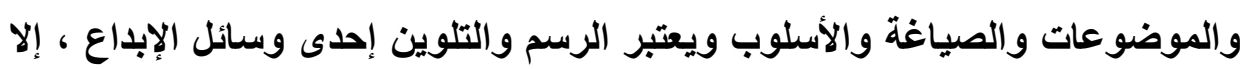
أنتا فى هذا البحث تخترق حدود الوسائل التقليدية فى التصوير وفى الألوان باختلاف

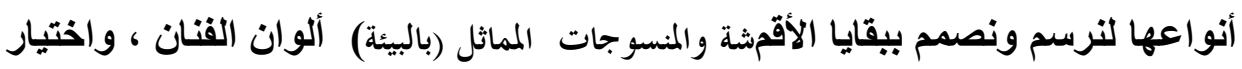
مايناسب منها التصميم أو الموضوع والتثبيث بالإبرة يماثل لمسات فرشاة القنان ، فالفرشاة هى الإبرة التى تسكن كل خيط أو قصقوصة على سطح القماش لتتج عملا 
تصويرياً يسمى بالفسيفساء القماشية وبالتالى تصبح الخيوط والأقمشة وسيلة إبداع

$$
\text { واحتراف وتقرد تبهر المتلقين . }
$$

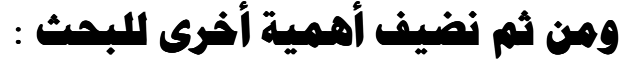

ـ - مساعدة الطلاب على العناية بمستواهم القنى والقدرة على التعبير بوسائط مختلفة.

ـ ممارسة المهارات اليلوية والفنية لإنتاج أعمال مبتكرة .

- إعمال الفكر لاى الطلاب وإمكاتية تقويمهم الأاتى لأعمالهم التطبيقية

ـ ـ أهمية التطبيقات التربوية إذ تنمى قوة إدراك الطلاب لخصائص ونوعية الخامات

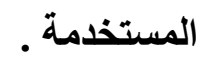

ويركز الباحث على الأساليب والتقتيات الفنية المتنوعة لإنتاج عمل فنى مميز ببقايا

المنسوجات ، كما يركز أيضاً على إمكانية إيجاد العلاقة الترابطية بين التعبيرات الفتية

للطلاب بالأثغال القتية التطبيقية وبالتالى الربط بين مادتى التصوير والنسجيات فى إلى قسم التربية الفتية ، ومن ثم يتم إعداد المعلم الذى تكون له القدرة على إعداد الخطط التربوية والفنية والتطبيقية وبالتالى يتم التوصل إلى الكثف عن العمليات العقلية

$$
\text { والفكرية والتعبيرية الناتجة من النشىع فى البيئة المصرية . }
$$

\section{ويوصى الباهث :}

- يجب المساهمة فى إيجاد حلول تساعد فى التخلص من التلوث البصرى كمطلب حضارى وقومى وعالمى •

- - تثجيع الطلاب على البحث عن جمال التكوين فى الطبيعة ومعرفة العناصر

الأساسية له من خطوط وأشكال وألوان وغير ها بالوسائط المتاحة.

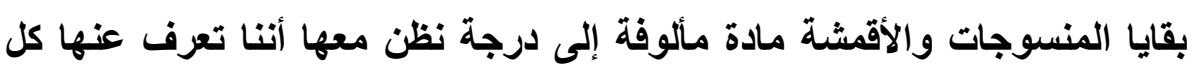
إمكانياتها فهى سهلة طيعة فى معالجتها لا تعوق التعبير ، وفى التصميم يجب على الطالب أن يطور قرته الخاصة بفهم المادة وأن يخرج عن طريقها مايتخيله . 